\title{
A narrative review on the use of lip trainer (Patakara) in oral rehabilitation
}

\author{
Corresponding author: \\ Ali Mohamed Ali Ismail, Department \\ of Physical Therapy for Cardiovascular/ \\ /Respiratory Disorder and geriatric, \\ Faculty of Physical Therapy, Cairo Uni- \\ versity, Giza, Egypt; \\ e-mail: ali.mohamed@pt.cu.edu.eg
}

Medical Research Journal 2021;

Volume 6, Number 2, 153-156

DOI: 10.5603/MRJ.a2021.0020

Copyright (C) 2021 Via Medica

ISSN 2451-2591

e-ISSN 2451-4101

\begin{abstract}
The spent time on body exercising is usually given more interest than the exercise of lips, especially after the wide evidence-based demonstrated effects of strong lips on the general health and hence the quality of life. Oral rehabilitation leads to a powerful closure of the lip that can be the first-line defensive mechanism against the many oral dysfunctions as halitosis, snoring, mouth breathing and dryness, and dysfunctions of the oro-gastrointestinal system. The strong lip seal or closure gained from the continuous use of lip muscle trainer (Patakara) not only limits the deteriorated normal physiological oral functions that are associated with the ageing process but also can be considered a good oral rehabilitation device to many oral dysfunctions such as halitosis, snoring, mouth breathing and dryness, and dysfunctions of the oro-gastrointestinal system. Incorporating the use of lip muscle trainer in traditional physiotherapy and rehabilitation programs - especially for geriatrics — is a fundamental part of the whole treatment plan. Physiotherapists must direct their attention toward Patakara utilization in future oral rehabilitation studies to augment and affirm more benefits for this hopeful device. Advising the family relative or caregivers to encourage the elderly to use the lip muscle trainer for maintaining a strong lip is very important.
\end{abstract} Key words: Patakara, oral rehabilitation, oral health, lip muscle trainer

Med Res J 2021; 6 (2): 153-156

\section{Introduction}

The complex feature of lip closure can be accomplished by the integration of variant numbers and types of movements of the orbicularis oris muscle (OOM), with additional face muscles that have fibres moving in all directions around the perioral complex [1]. Since it can influence various daily activities, the functional strong lip is vital to remember [2]. Many functions - such as talking, chewing, and swallowing - belong to the action of OOM [3].

The process of ageing-related steady decline in muscular quality, strength, and mass is the general definition of sarcopenia [4]. Sarcopenia-related functional and structural changes appear in all body parts involving the tongue and lip muscles, oral and perioral complexes, and oral sensation [5]. Increased ageing-related tooth loss is a predisposing factor for weak tongue and labial muscles [6]. Atrophy, smaller fascicles and bundles, and changed fibre shape are the main reported form and consistency ageing-related changes of OOM [7].
It is important to maintain an effective labial closure because the strength of OOM decreases with the ageing process, resulting in an incomplete labial closure and unhealthy oral medium due to the saliva evaporation. Weak labial closure and decreased tongue movements — in cerebrovascular neurological insults - negatively impact chewing, digestion, and swallowing in the oral cavity [3].

Strength of orofacial musculature and, hence a strong labial closure is gained by the repeated performance of oro-facial muscle contractions via electro-stimulation [8] or oral rehabilitation devices including lip muscle trainer (Patakara) [9]. Although Patakara is not a relatively new device, studies on it are very limited. This narrative analysis, therefore, seeks to discuss the benefits of Patakara on oral health.

\section{Origin and history of Patakara}

In the early 1900s, in the field of orthodontic therapy, with the help of orofacial muscular training, Rogers introduced oro-myofunctional appliances (OMFA) to 
the patients with growing maldentition to correct the unusual pattern of deglutition, treating the myofunctional and/or myoskeletal problems [10], focusing on the normal swallowing and nasal breathing, improving the balance of oro-facial musculature, and to promote mandibular development [11].

Oro-facial training is an individualized rehabilitation regimen of resisted or active free oro-facial movements. Oro-facial training aims to correct or affirm the normal tongue posture, treat the imbalance of facial musculature, regain the tongue-cheek muscular balance, correct the abnormal chewing and swallowing patterns, and normalize the neuromuscular functions of the oro-facial complex [12]. OMFA emerged the idea of OMT-based devices because in 2000 Dr Akihiro, a Japanese dentist, invented the Patakara. This is a simple, non-invasive, easy-to-use, oral-rehabilitation device used to enhance oral health (by strengthening labial closure), and hence the quality of life (QoL) of the elderly [13].

\section{Segments of Patakara}

The highly elastic plastic Patakara [14] is made from a polyester-elastomer material (this material is a very highly elastic rubber-polymer-plastic composite) [9]. Due to its resilience, Patakara is designed to be placed between the upper and lower lips in the oral cavity to improve the conditioning of oral musculature [14]. Patakara consists of two parts: the first part (enters that oral cavity and is called as Pataleara which is considered as the fundamental big part with two sides, upper and lower sides) and the second part (plastic tabs) (Fig. 1).

\section{Guidelines of Patakara use}

Firstly, close the mouthpiece. Insert the Pataleara between teeth and lips. Without clenching the teeth, the person must contact the upper side to the lower side of Pataleara via closing lips for five minutes. During this time, the patient is ordered to constantly touch the tip of the tongue to the incisive papilla. During the five-minute lip closure, the person is ordered to perform at least 10-repetition stretching-movement by maximally drawing the plastic tabs of Patakara to front, right, left, upper, and lower directions without letting the device to be released from the oral cavity (this can be applied by the continuous firm closure of upper and lower lips during the exercise). This five-minute session may be repeated 5 times daily [15].

\section{Patakara indications}

Patakara can be used to address many oral dysfunctions as snoring, mouth breathing and dryness, halitosis, and oro-gastrointestinal dysfunction [13].

\section{Restoring the normal breathing from the nose}

Respiration is normally conducted from the nose. Conduction of respiration from the mouth or nose and mouth more than six months is defined as the habit of mouth breathing (MB). MB is related to ageing-related OOM and labial closure weakness, halitosis, mouth dryness, dental caries [16], the tongue's low resting position, weakness of oro-facial muscles [17], and dysfunction of dilating muscles of airways that present in obstructive sleep apnoea (OSA) [18].

OOM is the fundamental muscle included in the labial closure. From the middle of the fifth age decade, labial closure strength (LCS) begins to decrease to meet its minimum value at over 80 years [19]. Weak LCS and tongue elevation induce mouth breathing and snoring during sleeping. The gained appropriate LCS and tongue elevation by Patakara correct the breathing from oral to the nasal pattern. Patakara declines the apnoeic symptoms in patients with OSA by increasing the strength and force of OOM [15] in addition to improving the oxygen saturation [20].

\section{Snoring problem}

In the elderly, snoring is a very common health problem with some related risk factors, such as obesity and a large neck circumference [21]. It is understood that during sleep, most snorers exhibit a pattern of mouth breathing. Snoring can be theoretically decreased by increasing the pharyngeal airway space by shifting the tongue anteriorly to recompense for the lost neuromuscular function of genioglossus muscle (the main muscle of pharyngeal opening) [22]. Repetitive anterior placement of the tongue to the incisive papilla during the $\mathrm{Pa}-$ takara oral training may enlarge the upper airway space. Wide upper airway space corrects snoring by shifting the breathing pattern from oral to nasal breathing [15].

\section{Halitosis (bad mouth malodour)}

Halitosis negatively affects the social and psychological QoL in many subjects suffering from this embarrassing health problem [23, 24]. Development of malodorous substances and, hence halitosis is produced from the dry mouth that induces the growth of anaerobic and gram-negative bacteria. OSA, ageing, mouth breathing [20], and systemic disorders such as diabetes [25] are commonly associated with dry mouth. Using Patakara increases saliva flow [20] that eliminates halitosis by lowering the number of oral bacteria and enhancing the wetness of oral mucosal tissue in geriatrics [26]. Also, increased upper airway space in patients with OSA in addition to the return to normal nasal breathing pattern [15]. 


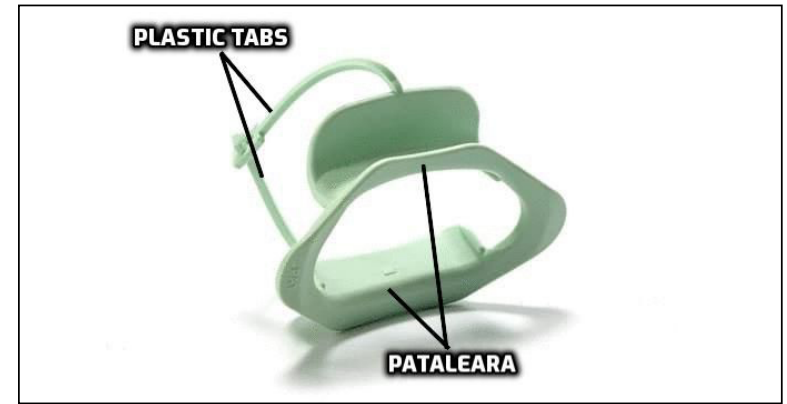

Figure 1. Segments of Patakara

\section{Mouth dryness}

The subjective symptom of decreased saliva secretion is the definition of dry mouth or xerostomia, whereas the objective finding of low saliva flow is hyposalivation $[25,27]$. Xerostomia and hyposalivation are risk factors for periodontitis, dental caries, local oral and systemic infections, feeding and swallowing problems, and upper gastrointestinal dysfunctions [28].

Oral training by Patakara can improve the saliva flow, wetness of oral mucosa [14], and oral pain that may present in geriatric-related chronic periodontitis [26]. Hypofunction of the salivary reflex arch (afferent arm, salivary nucleus, and efferent arm) in addition to the progressive cellular loss of the motor nervous system (including the facial nerve and its supplying facial muscles) — is reported with the ageing process. Repeated contractions and stretching to oro-facial muscles - with the help of Patakara training-trigger the afferent receptors and branches of the facial nerve in facial muscles that, in turn, stimulate the salivary nucleus in the brain that activate the efferent arm (salivary glands) to increase the production saliva flow [14].

\section{Oro-gastrointestinal dysfunctions}

Ageing-associated physiological hypofunctions occur in many physiological processes of the body including swallowing. This changed swallowing process in the elderly occurs due to the declined neuromuscular reserve [29], teeth loss, less-efficient mastication, decreased density and cross-sectional area of jaw muscles [30], declined volume and pressure of tongue muscle (it produces the adequate force to transit the chewed food parts to the pharynx), down-shifted location of the larynx in some geriatrics, the overspread of pharynx cavity, and the large-timed and small-sized opening of the upper-oesophageal sphincter [29].

The involved tongue isometric strengthening exercises [31] during Patakara training [15] can improve swallowing dysfunctions. The repeated isometric ex- ercises of the tongue can improve the ageing-related declined capacity of motor functions of the tongue, enhance tongue pressure and strength, control the food bolus, and hence improve the dietary-intake functions in the geriatric mouth [32].

In eating disorders, Patakara can boost the geriatric QoL as the oro-facial muscle training can boost nasal respiration due to the corrected integration between the nasal cavity, the location of the tongue, the larynx, and the airways. Patakara-induced parasympathetic stimulation may be the cause of improved salivation in addition to the enhanced subjective symptoms of gastrointestinal dysfunction such as epigastralgia, early satiety, constipation, and anorexia especially in geriatrics with poor nutrition [19].

To gain the normal dietary functional intake, it is noted that using food in oral rehabilitation raises the risk of pulmonary aspiration. The frequent use of a lip muscle trainer (Patakara) in the rehabilitation of oral and/or eating dysfunctions can lower the risk of pulmonary aspiration and further raises the value of geriatric lip closure training [33].

\section{Conclusions}

The strong lip seal/closure gained from the continuous use of lip muscle trainer (Patakara) not only limits the deteriorated normal physiological oral functions that are associated with the ageing process but also can be considered a good oral rehabilitation device to many oral dysfunctions such as halitosis, snoring, mouth breathing and dryness, and dysfunctions of the oro-gastrointestinal system. Physiotherapists must direct their attention toward Patakara utilization in future oral rehabilitation studies.

\section{Conflict of interests: The author declares no conflicts of interest.}

\section{References}

1. Fındık $Y$, Baykul T, Aydın MA, et al. Evaluation of lip force in patients with unilateral and bilateral cleft lip. Br J Oral Maxillofac Surg. 2017; 55(4): 391-395, doi: 10.1016/j.bjoms.2016.12.015, indexed in Pubmed: 28087210

2. Wong V, Abe T, Spitz R, et al. Effects of age, sex, disease, and exercise training on lip muscle strength. Cosmetics. 2020; 7(1): 18, doi: 10.3390/cosmetics7010018.

3. Yanagisawa $\mathrm{Y}$, Matsuo $\mathrm{Y}$, Shuntoh $\mathrm{H}$, et al. Effect of expiratory resistive loading in expiratory muscle strength training on orbicularis oris muscle activity. J Phys Ther Sci. 2014; 26(2): 259-261, doi: 10.1589/jpts.26.259, indexed in Pubmed: 24648644.

4. Fukada K. Kajiya K. Age-related structural alterations of skeletal muscles and associated capillaries. Angiogenesis. 2020; 23(2): 79-82 doi: 10.1007/s10456-020-09705-1, indexed in Pubmed: 31993832.

5. Al-Drees A. Oral and perioral physiological changes with ageing Pakistan Oral Dent J. 2010; 30(1). 
6. Kim SH, Kim MJ, Lee SH, et al. The effects of orofacial myofunctiona training on the changes of lip and tongue strength in elderly people. Journal of Dental Hygiene Science. 2019; 19(4): 279-287, doi: 10.17135/jdhs.2019.19.4.279.

7. Penna V, Stark G-, Eisenhardt SU, et al. The aging lip: a comparative histological analysis of age-related changes in the upper lip complex. Plast Reconstr Surg. 2009; 124(2): 624-628, doi: 10.1097/PRS.0b013e3181addc06, indexed in Pubmed: 19644283

8. Abe T, Wong V, Spitz RW, et al. Influence of sex and resistance training status on orofacial muscle strength and morphology in healthy adults between the ages of 18 and 40: A cross-sectional study. Am J Hum Biol. 2020; 32(6): e23401, doi: 10.1002/ajhb.23401, indexed in Pubmed: 32030840.

9. Ibrahim F, Arifin N, Rahim Z. Effect of orofacial myofunctional exercise using an oral rehabilitation tool on labial closure strength, tongue elevation strength and skin elasticity. Journal of Physical Therapy Science. 2013; 25(1): 11-14, doi: 10.1589/jpts.25.11.

10. Papageorgiou SN, Koletsi D, Eliades T. What evidence exists for myofunctional therapy with prefabricated appliances? A systematic review with meta-analyses of randomised trials. J Orthod. 2019; 46(4): 297-310, doi: 10.1177/1465312519880558, indexed in Pubmed: 31597520

11. Boucher C, Charezinski M, Balon-Perin A, et al. Benefits of using a Trainer T4K®myofunctional appliance after rapid palatal expansion: a prospective study on thirteen patients. Journal of Dentofacia Anomalies and Orthodontics. 2010; 11(1): 30-44, doi: 10.1051/odfen/20084210037.

12. Idris G, Hajeer MY, Al-Jundi A. Soft- and hard-tissue changes following treatment of Class II division 1 malocclusion with Activator versus Trainer: a randomized controlled trial. Eur J Orthod. 2019; 41(1): 21-28, doi: 10.1093/ejo/cjy014, indexed in Pubmed: 29617755

13. Liptrainerguru.com. https://liptrainerguru.com/ (2021 February 01)

14. Saleem M, Yoshinari N, Nakamura S, et al. Improvement of salivary flow and oral wetness by a lip trainer device and sonic toothbrush in older Japanese men and women with dry mouth. J Oral Sci. 2019 61(2): 221-228, doi: 10.2334/josnusd.18-0012, indexed in Pubmed 30930355.

15. Suzuki $H$, Yoshimiura M, Iwata $Y$, et al. Lip muscle training improves obstructive sleep apnea and objective sleep: a case report. Sleep Sci. 2017; 10(3): 128-131, doi: 10.5935/1984-0063.20170022, indexed in Pubmed: 29410742

16. Kimura-Ueda K, Shimazaki K, Sugimoto K, et al. Influence of habitual mouth breathing on taste sensation. Orthodontic Waves. 2019; 77(1) 24-30, doi: 10.1016/j.odw.2017.12.003.

17. Cassir N, Desplats E, Rompré P, et al. Efficacy and stability of orofacial myofunctional therapy on restoring mature pattern of swallowing and nasal breathing in children before orthodontic treatment: a randomized trial. Thesis at University of Montreal. 2016. http://hdl.handle. net/1866/16429 (2021 February 01)

18. O'Connor Reina C. Plaza Mayor G, Ignacio-Garcia JM, et al. Floppy Closing Door Epiglottis Treated Successfully with an Mhealth Application Based on Myofunctional Therapy: A Case Report. Case Rep Otolaryngol. 2019; 2019: 4157898, doi: 10.1155/2019/4157898, indexed in Pubmed: 31355035.

19. Ishikawa M, Ishikawa S, Kamata H, et al. Efficacy of a Health Promotion Program with facial mimetic muscle training in residents of a medical care facility for the elderly. ANTI-AGING MEDICINE. 2010; 7(11): 120-128, doi: 10.3793/jaam.7.120.

20. Yoshimiura $M$, Suzuki $H$, Tanaka $H$, et al. Lip muscle training improves halitosis and obstructive sleep apnea syndrome: a case report. Journal of Dental Sleep Medicine. 2016; 03(01): 31-32, doi: 10.15331/jdsm.5372

21. Adebusoye LA, Ogunbode AM, Olowookere OO. Factors associated with reported snoring among elderly patients attending the geriatric centre in Nigeria. Pan Afr Med J. 2014; 19: 309, doi: 10.11604/pamj.2014.19.309.5244, indexed in Pubmed: 25883736.

22. Engelke W Engelhardt W Mendoza-Gartner M et al. Functional treatment of snoring based on the tongue-repositioning manoeuvre. The European Journal of Orthodontics. 2010; 32(5): 490-495, doi: 10.1093/ejo/cjp135

23. Lu HX, Chen $X L$, Wong $M$, et al. Oral health impact of halitosis in Chinese adults. Int J Dent Hyg. 2017; 15(4): e85-e92, doi: 10.1111/idh.12242, indexed in Pubmed: 27516401.

24. Przybyszewska-Pardak S, Groch M, Loster J, et al. Assessment of dental condition in young Polish adults using the BEWE index. Family Medicine \& Primary Care Review. 2020; 22(4): 307-311, doi: 10.5114/fmpcr.2020.98256.

25. Ismail AMA, Ezz Eld, AbdelAal MEM. Impact of transcutaneous electrical nerve stimulation (TENS) on hyposalivation in type 2 diabetics. Biosci Res. 2019; 16(1): 690-694.

26. Akinori M, Keita K, Kiyohito K. The Effect of the oral environmental improvement by the oral myofunctional therapy for elderly patients with chronic periodontitis. The Japanese J Conserv Dent. 2014; 57(2): 180-187, doi: 10.11471/shikahozon.57.180.

27. Ismail AMA. Hyperbaric oxygen therapy as a complementary or alternative therapy for chronic oral and gastrointestinal disorders: A narrative review. International Journal of Alternative and Complementary Medicine. International Journal of Alternative and Complementary Medicine. 2020: 33-40

28. Kandelman D, Petersen PE, Arpin S, et al. Oral health, general health, and quality of life in older people. Spec Care Dentist. 2008; 28(6): 224-236, doi: 10.1111/j.1754-4505.2008.00045.x, indexed in Pubmed: 19068063

29. Chiba Y. Short-term effectiveness of a swallowing exercise for the elderly using day-care services. Journal of Nursing \& Care. 2013; 5 , doi: 10.4172/2167-1168.s5-012.

30. Weijenberg RAF, Scherder EJA, Lobbezoo F. Mastication for the mind--the relationship between mastication and cognition in ageing and dementia. Neurosci Biobehav Rev. 2011; 35(3): 483-497, doi: 10.1016/..neubiorev.2010.06.002, indexed in Pubmed: 20547177.

31. Langmore SE, Pisegna JM. Efficacy of exercises to rehabilitate dysphagia: A critique of the literature. Int J Speech Lang Pathol. 2015; 17(3): 222-229, doi: 10.3109/17549507.2015.1024171, indexed in Pubmed: 25825989

32. Safi MF, Wright-Harp W, Lucker JR, et al. Effect of neuromuscular electrical stimulation on labial and lingual weakness. Top Geriatr Rehabil. 2018; 34(2): 145-154, doi: 10.1097/TGR.0000000000000185.

33. Takamoto K, Saitoh T, Taguchi T, et al. Lip closure training improves eating behaviors and prefrontal cortical hemodynamic activity and decreases daytime sleep in elderly persons. J Bodyw Mov Ther. 2018; 22(3): 810-816, doi: 10.1016/j.jbmt.2017.09.002, indexed in Pubmed: 30100317 